\title{
Helminth Therapy for Immune-Mediated Inflammatory Diseases: Current and Future Perspectives
}

\author{
Wenjie Shi $\mathbb{D}^{1, *}$, Ning Xu $\mathbb{D}^{1, *}$, Xuelin Wang', Isabelle Vallée ${ }^{2}$, Mingyuan Liu', Xiaolei Liu' \\ 'Key Laboratory of Zoonosis Research, Ministry of Education, Institute of Zoonosis, College of Veterinary Medicine, Jilin University, Changchun, \\ 130062, People's Republic of China; ${ }^{2}$ UMR BIPAR, Anses, INRAE, Ecole Nationale Vétérinaire d'Alfort, Laboratoire de Santé Animale, Maisons-Alfort, \\ France
}

Correspondence: Xiaolei Liu; Mingyuan Liu, Tel +86-15943092280; +86-13019125996, Email liuxlei@163.com; liumy36@I63.com

*These authors contributed equally to this work

\begin{abstract}
Inflammatory bowel disease and allergic asthma, as typical immune-mediated inflammatory diseases (IMIDs), are associated with immune imbalance caused by complex interactions among environmental, genetic and bacterial factors. The changing immune imbalance of IMIDs not only causes serious pathological damages but also increases the difficulty of treatment. Helminths or helminth-derived molecules have been increasingly employed to treat IMIDs due to their immunoregulatory ability. Since helminth infection is not an appropriate treatment direction due to the complex immunoregulation and safety concerns, one of the new therapies is to harness the immunoregulation induced by the identified helminth-derived molecules using immune indexes as a guide. This review discusses the pathogenesis of inflammatory bowel disease and allergic asthma, and summarizes the therapeutic effect of helminths and the immunoregulatory mechanisms induced by helminth-derived molecules proposing therapeutic regimens.
\end{abstract}

Keywords: inflammatory bowel disease, allergic asthma, immunoregulation, IMIDs, helminth therapy, helminth-derived molecules

\section{Introduction}

Helminths, as ancient organisms, have existed throughout the history of human evolution and formed perfect ways to escape the immune response by interacting with the human immune system for a long time. The helminth-induced immune microenvironment can not only reduce the damage caused by invasion but also allow helminths to take advantage to their own survival and reproduction. ${ }^{1}$ The improvement of health care, deworming and clean environments resulted in a low prevalence of helminth infection accompanied by an increasing incidence of immune-mediated inflammatory diseases (IMIDs), such as inflammatory bowel disease (IBD), allergic asthma and atopic dermatitis. ${ }^{2}$ This negative correlation between helminth infections and IMIDs also agrees with the hygiene hypothesis ${ }^{3}$ and the socalled old friend hypothesis, ${ }^{4}$ both of which propose that recent increases in inflammatory diseases are partly linked to a lack of exposure to microorganisms. Therefore, the immunoregulation of helminths has great potential in treating IMIDs. IMIDs are characterized by an imbalance of $\mathrm{CD}^{+} \mathrm{T}$ cell subsets, including $\mathrm{T}$ helper type 1 (Th1) cells, $\mathrm{T}$ helper type 2 (Th2) cells, T helper type 17 (Th17) cells, T follicular helper (Tfh) cells B regulatory (Breg) cells and T regulatory (Treg) cells. ${ }^{5}$ Human infection with Filaria showed the proliferation of Treg cells and Th17 cells, and the significantly increase in IL-10 and IL-17A. ${ }^{6}$ Although Necator americanus or Trichuris suis therapies were effective for partly patients with IBD, the vast majority of trials of helminth therapy showed no clinical effect on IMIDs. ${ }^{7,8}$ Trichuris suis did not improve pollen-induced allergic rhinitis in clinical trials, ${ }^{9,10}$ and Necator americanus did not improve airway responsiveness in patients with asthma. ${ }^{11}$ Traditional helminth therapy is completely dependent on the pathogen infection, showing that excretory-secretory products (ESPs) are responsible for helminths to regulate the host's immune system. The immune response induced by ESPs is multitudinous and unpredictable due to the complexity of the 
components, resulting in uncertain therapeutic effect. ${ }^{12-14}$ In addition, another explanation is that helminth therapy may be a large difference in the prevention and treatment of IMIDs. The host' s immune response induced by helminths may reduce susceptibility to IMIDs rather than treat IMIDs. ${ }^{15}$ Nevertheless, the therapeutic value of helminth-derived molecules can not be ignored. Although the limited research on the immunomodulatory mechanism of helminthderived molecules, the treatment of IMIDs based on helminth-derived molecules has great prospects.

IBD and allergic asthma, two typical IMIDs, are prevalent worldwide. At present, there is still a lack of effective treatments for immune imbalance and patients suffer recurrence of clinical symptoms. This review summarizes the pathogenesis of IBD and allergic asthma, the therapeutic effects of helminths and helminth-derived molecules, and the immunoregulatory mechanism of helminth-derived molecules.

\section{Inflammatory Bowel Disease Symptoms and Pathogenesis}

IBD is a chronic bowel disease characterized by abdominal pain, blood in the stool and weight loss, including Crohn's disease and ulcerative colitis. ${ }^{16}$ In recent years, the incidence of IBD has increased worldwide, but current treatments only improve symptoms and they are not fundamental therapies for IBD. ${ }^{17}$ Therefore, it is necessary to find new therapeutic strategies to achieve better treatment results.

IBD is associated with complex interactions among environmental, genetic and bacterial factors (Figure 1). It has been known that incidence rates increase if a group of people move from regions with low incidence rates of IBD to high prevalence areas. ${ }^{18}$ Therefore, changes in the living environment are associated with reduced susceptibility to IBD. With the development of the economy, human life patterns have undergone significant changes, such as unbalanced diet structure, tobacco dependence, insufficient exercise, and drug abuse. These changes can disrupt the balance between the immune response and immune tolerance, which are associated with the increasing incidence rate of IBD. ${ }^{19-21}$

Genomics has found 163 genes related to the pathogenesis of IBD, including nucleotide-binding oligomerization domain 2 (Nod2), interleukin-10 receptor (IL-10R), caspase recruitment domain family member 9 (CARD9), interleukin23 receptor (IL-23R) and protein tyrosine phosphatase non-receptor type 2 (PTPN2). ${ }^{22,23}$ Nod2 is an important intracellular receptor to regulate gut microbiota. ${ }^{24}$ After activation by muramyl dipeptide derived from bacterial proteoglycan, Nod2 activates the nuclear factor kappa-light-chain-enhancer of activated B cells (NF- $\mathrm{BB}$ ) signaling pathway to produce antimicrobial peptides such as $\alpha$-defensins in Paneth cells ${ }^{25}$ (Figure 2). These peptides can directly regulate gut microbiota, which affect the development of intestinal inflammation. ${ }^{26,27}$ It has also been reported that Nod2 signaling in CD11 $\mathrm{c}^{+}$cells can drive the Th2-type immune response with the synergistic signals of tumor necrosis factor receptor superfamily member 4 ligand (OX40L) and thymic stromal lymphopoietin receptor (TSLPR). ${ }^{28}$ Mutations in NOD2 lead to decreased the level of IL-10, but increase in mucosal bacteria. The decreased level of IL-10 causes disruption of the mucosal barrier and reduces susceptibility to colitis. ${ }^{29}$ Consistently, patients with defective Nod2 show chronic inflammation driven by interleukin 12 (IL-12) and interferon-gamma (IFN- $\gamma$ ). ${ }^{30}$ Mutations in genes encoding the IL10R subunit proteins are found in patients with early-onset enterocolitis, leading to hyperinflammatory immune

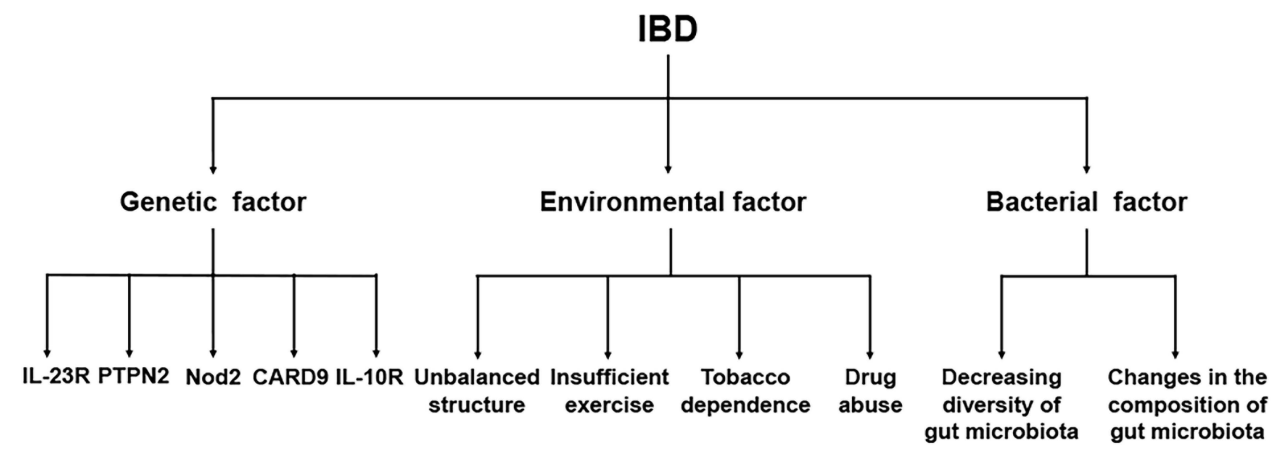

Figure I Classification of factors that can induce IBD. 


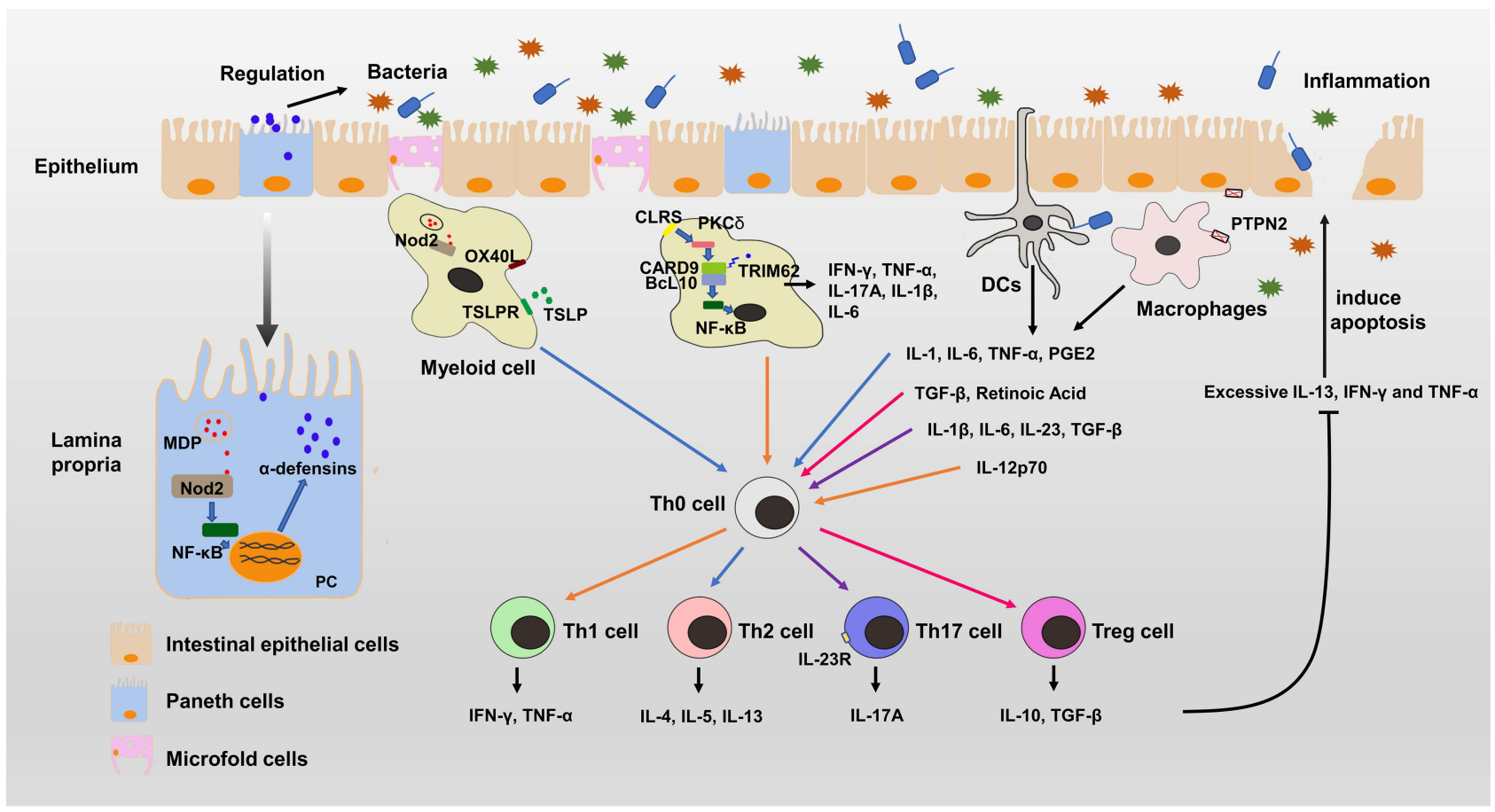

Figure 2 The pathogenesis of IBD. Nod2 is highly expressed in Paneth cells and myeloid cells. Nod2 activated by muramyl dipeptide can activate the NF- $\mathrm{B}$ pathway to produce $\alpha$-defensins that directly regulate gut bacteria in Paneth cells. Nod2 signaling can drive the Th2-type immune response with the synergistic signals of OX40L and TSLPR. CARD9 is highly expressed in myeloid cells and can activate the NF- $\kappa B$ pathway to secrete pro-inflammatory cytokines such as IFN- $\gamma$, TNF- $\alpha$, IL-I7A, IL-I $\beta$ and IL- 6 . When CARD9 mutates to CARD9 ${ }^{\mathrm{SI} 2 \mathrm{~N}}$, it can induce a Th2-type immune response. The IL-23 signaling pathway of ThI7 cells is critical in the development of IBD. PTPN2 mediated interactions between intestinal epithelial cells and macrophages are necessary for maintaining the intestinal barrier function. The gut bacteria also affect the immune system by interacting with immune cells. DCs can induce Th0 cells to differentiate by producing different cytokines. Immune imbalance can cause excessive IL-I3, IFN- $\gamma$ and TNF- $\alpha$ to induce apoptosis of intestinal epithelial cells. Destruction of the intestinal barrier and invasion of the gut microbiota further leads to severe inflammation.

responses in the intestine. ${ }^{23}$ CARD9 is a signaling adaptor protein downstream of many C-type lectin receptors and is highly expressed in B cells, T cells and myeloid cells. ${ }^{31}$ It has been reported that phosphorylation of CARD9 mediated by activated protein kinase $\mathrm{C}-\delta$ can form the CARD9-BcL10 complex to activate the NF- $\mathrm{KB}$ pathway. ${ }^{32}$ Meanwhile, the ubiquitination of CARD9 mediated by the ubiquitin ligase TRIM62 is essential for CARD9 activity. ${ }^{33}$ CARD9 exon 11 integrity is critical for the formation of CARD9-BcL10 complex and maintains the number of lymphocytes and myeloid cells. ${ }^{34}$ CARD9 signaling pathway can maintain intestinal immune homeostasis and gut microbiota, and mice with CARD9 deficiency have increased susceptibility to colitis. ${ }^{35}$ IL-23 secreted by monocytes can activate IL-23R on the surface of immune cells and produce a large number of pro-inflammatory cytokines, such as IL-6, IFN- $\gamma$ and tumor necrosis factor (TNF). ${ }^{36}$ In addition, the interaction mediated by PTPN2 between intestinal epithelial cells and macrophages is necessary for maintaining the intestinal barrier function. Loss of PTPN2 in macrophages can promote classical activation of macrophages. ${ }^{37}$ Excessive cytokines $\left(\mathrm{TNF}^{38}{ }^{3 F N-} \gamma^{39}\right)$ can induce apoptosis of intestinal epithelial cells and result in destruction of the intestinal barrier.

It should not be forgotten that the interaction between gut microbiota and intestinal tissue directly affect intestinal immune homeostasis (Figure 2). The antigen of gut microbiota can be taken up by mononuclear phagocytes via microfold cell-mediated transcytosis. Furthermore, Dendritic cells (DCs), under inflammatory stimulation, can send dendrites outside the epithelium and capture gut microbiota. ${ }^{40}$ Many studies found that the gut microbiota in patients and mouse models showed less diverse with fewer Faecalibacterium prausnitzii or Roseburia, but with a significantly increased level of Escherichia coli, Bacteroides vulgatus, Alistipes putredinis and Ruminococcus gnavus. ${ }^{41-43}$ Meanwhile, butyrate derived from Faecalibacterium prausnitzii and Roseburia could induce Treg cells to alleviate intestinal inflammation. ${ }^{44}$ Altered gut microbiota disturbs intestinal immune homeostasis and is associated to the development of IBD. 


\section{Drawbacks of Existing Treatments for IBD}

The mainstay of clinical therapies for IBD includes 5-aminosalicylic acid, steroids, biological agents (anti-TNF- $\alpha$ antibodies), exclusive enteral nutrition and surgery. ${ }^{45,46}$ However, long-term administration of 5-aminosalicylic acid and steroids induces inflammation of the heart or pericardium and osteoporosis, although they can relieve pathological symptoms of IBD. ${ }^{47}$ Few patients are suitable for biological therapy, which will increase the risk of infection and tumors. ${ }^{48}$ Therefore, there is an urgent need to find a therapy with high safety.

\section{Allergic Asthma}

\section{Symptoms and Pathogenesis}

Allergic asthma is a subset of asthma, when patients are exposed to allergens, allergic asthma patients have symptoms such as wheezing, increasing airway mucus and airway hyperresponsiveness. ${ }^{49}$ At the present, the prevalence of allergic asthma is steadily increasing worldwide, which brings medical and economic pressure to the individual and nations. ${ }^{50,51}$

Allergic asthma is a complex disease caused by genetic and environmental factors. It has been reported that children from families with a genetic background of allergic asthma suffer from the disease more easily than those from families without any history of allergic asthma. ${ }^{52}$ Besides, a large number of genes are associated with allergic asthma, such as IL33, ST2, TLR2, Nod2, IL-10, GATA3 and STAT6. ${ }^{53,54}$ IL-33/ST2 signaling pathway stimulates ILC2s and eosinophil proliferation and is associated with susceptibility to allergic asthma. ${ }^{55}$ Antibodies targeting ST2 have been used in clinic and achieved remarkable results. ${ }^{56}$ In addition, the living environment is a non-negligible factor in the development of allergic asthma. Epidemiological investigations have shown that the incidence rate of allergic asthma in children exposed to multiple bacteria in childhood is obviously lower than that in children with limited bacterial exposure. ${ }^{57}$ Consistent with this, in a mouse model, low-dose LPS stimulation could prevent allergic asthma symptoms induced by house dust mites, which supported the protective effect of the immune response induced by microflora in allergic asthma. ${ }^{58}$

The allergic reaction involves sensitization and effector stages (Figure 3). After stimulation with inhaled allergens, airway epithelial cells secrete large amounts of IL-25, IL-33, and TSLP, which can induce group 2 innate lymphoid cells (ILC2s) and Th2 cells to proliferate and secrete large amounts of IL-4, IL-5, and IL-13 and result in a strong Th2 immune response. ${ }^{59}$ In addition, allergens processed by DCs can promote the differentiation of $\mathrm{Tfh}$ cells, which can induce plasmacytes to produce IgE in the germinal center. ${ }^{60}$ When IgE binds to Fc receptors, mast cells are activated and release histamine, leukotriene, IL-5, and IL-13. IL-5 recruits more eosinophils into the lung tissue with the synergistic effect of chemokines CCL11 and CCL24. Eosinophils can aggravate lung allergic inflammation by releasing IL-4, IL-5, IL-13, IFN- $\gamma$, CCL3, and CCL5. ${ }^{61}$ IL-17A secreted by Th17 cells can induce airway smooth muscle contraction and stimulate epithelial cells to release CCL1, CCL2, and CCL5. These chemokines can recruit neutrophils into lung tissue and cause severe inflammation. ${ }^{62}$ Neutrophils and macrophages can secrete matrix metalloproteinase 9 to induce airway hyperresponsiveness. ${ }^{63}$ When patients are exposed to allergens again, mast cells can be activated by IgE on their surface and quickly cause immune imbalance to induce an inflammatory response.

\section{Changed Immune States in Different Stages of Allergic Asthma}

It has been reported that childhood-onset patients show increasing levels of IL-4 and decreasing levels of IFN- $\gamma$, which are similar to characteristics of allergic reactions. ${ }^{64}$ When allergic asthma develops into severe allergic asthma, it is often associated with mixed inflammation induced by Th2-type, Th17-type, and Th1-type immune responses. In clinical experiments, increasing levels of IL-4 and IFN- $\gamma$ are found in the airway, bronchoalveolar lavage (BAL) and supernatant of whole-blood culture of patients with allergic asthma. ${ }^{65,66}$ Consistent with this, in a mouse model of ovalbumin (OVA)induced allergic asthma, the levels of IL-4, IL-17A and IFN- $\gamma$ in lung $\mathrm{CD}^{+} \mathrm{T}$ cells are higher than those in the control group. ${ }^{67}$

\section{Drawbacks of Existing Treatments for Allergic Asthma}

Current clinical treatment options for allergic asthma include allergen immunotherapy, glucocorticoids and bronchodilators. ${ }^{68,69}$ In recent years, with further studies on the pathogenesis of allergic asthma, biological agents 


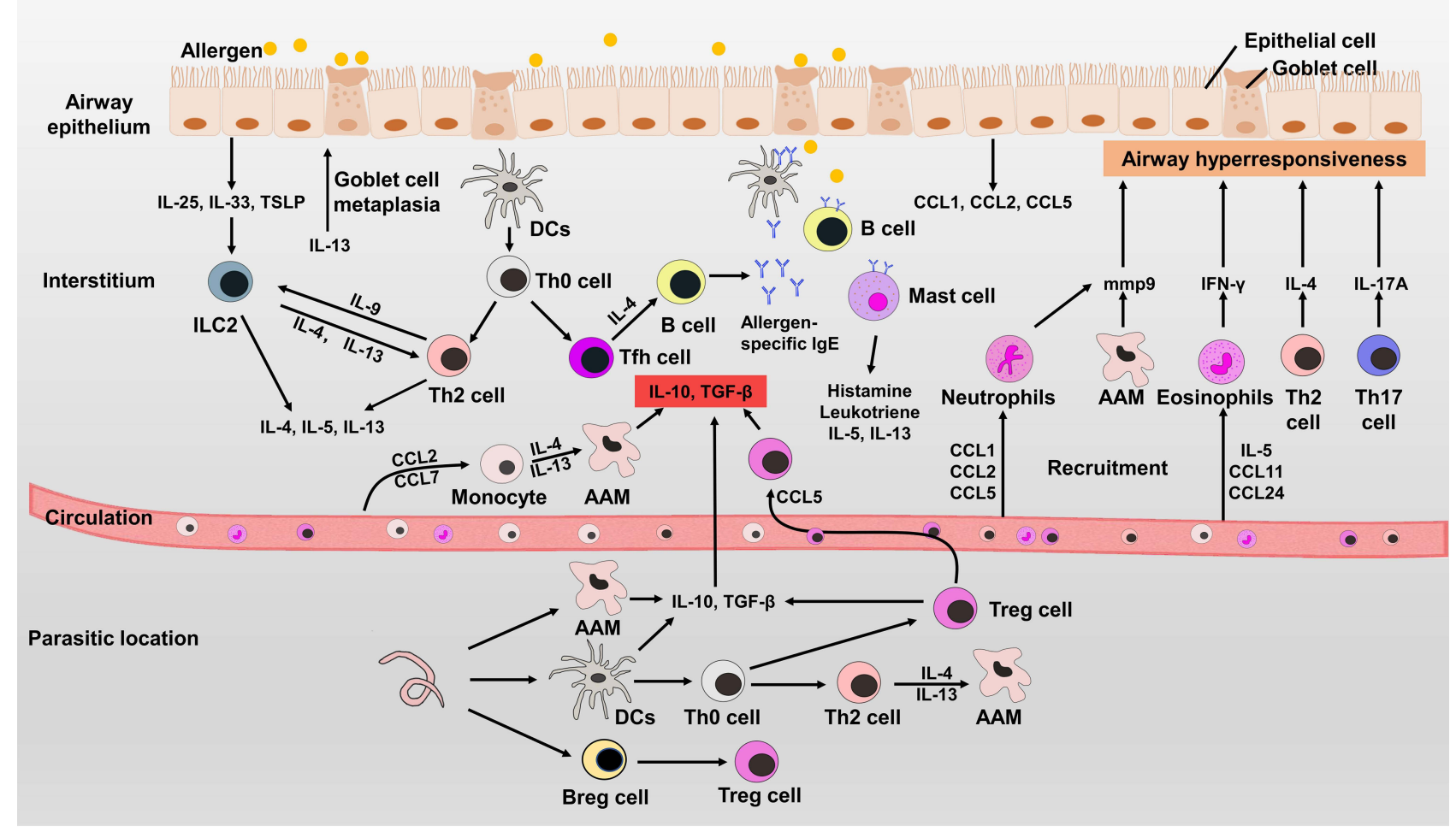

Figure 3 The pathogenesis of allergic asthma and the mechanisms of helminth therapy. When the immune system encounters allergens for the first time, airway epithelial cells activate ILC2s to induce a Th2-type immune response. Antigen presenting cells can also present allergens to Th0 cells and induce the differentiation of Th2 cells and Tfh cells. Tfh cells and IL-4 can induce B cells to produce allergen-specific lgE that binds to Fc receptors on mast cells, B cells and DCs. Eosinophils are recruited by IL-5 and release IFN- $\gamma$, which is involved in airway hyperresponsiveness. IL-I7A and matrix metalloproteinase 9 also contribute to airway hyperresponsiveness. Upon subsequent exposure to allergens, immune cells can be quickly activated to cause inflammation. Helminths and helminth-derived molecules can induce the differentiation of Treg cells and anti-inflammatory cytokines in the parasitic location. Although some helminths are not exposed to lung tissue, the regulated immune cells that secret anti-inflammatory cytokines can migrate to inflammatory tissues to suppress the inflammation in lungs.

targeting key immune effectors have been widely used in clinical applications, such as anti-IL-5 biologics and anti-IgE monoclonal antibodies. ${ }^{70}$ However, all these therapies have drawbacks, such as side effects of glucocorticoids and impairment of the immune system caused by biological agents. ${ }^{71,72}$

\section{Advantages and Limitations of Helminth Therapy for IMIDs}

As an ancient species, helminths have evolved complete mechanisms of immune evasion. The invasion of helminths causes epithelial tissue damage with the production of numerous endogenous substances. ${ }^{73}$ Endogenous substances activate damage-associated molecular pattern molecules. Besides, secondary bacterial infection activates pathogenassociated molecular pattern molecules. These two processes together cause inflammation induced by the Th1-type immune response. However, ESPs released during helminth infection can induce immunosuppression and Th2-type immune response to promote tissue repair to reduce pathological damage. This immunomodulatory ability can be used to inhibit inflammation of IMIDs. Nevertheless, the abundance and composition of ESPs vary significantly at every stage of helminths development, which is consistent with the wide varieties of helminth-induced immune responses. Therefore, helminth infection is not an appropriate treatment direction due to the complex immunoregulation and safety concerns.

\section{Helminth Therapy for IBD}

At present, experimental studies have widely adopted chemical reagent-induced models of IBD in mice, such as Trinitrobenzene sulfonic acid (TNBS), dinitrobenzene sulfonic acid (DNBS), dextran sulfate sodium salt (DSS) and piroxicam. These chemical reagents can induce epithelial lesions in the colon, CD4+ T cell infiltration in the intestinal lamina propria and high levels of IFN- $\gamma \cdot{ }^{74}$ TNBS-treated mice infected with Schistosome eggs could inhibit Th1-type inflammation dependent on IL-4 signaling pathway and alleviate the pathology of the colon. ${ }^{75}$ When TNBS-treated mice 
were infected with Trichinella spiralis, colon homogenate supernatants showed more IL-4 but less IFN- $\gamma$ than control mice, which can alleviate the pathological damage caused by Th1-type inflammation in the colon. ${ }^{76}$ The soluble molecules from the eggs of Schistosoma mansoni and ESPs of Ancylostoma caninum counteracted the detrimental effects of IFN- $\gamma$, IL-12 induced by DSS in mouse serum and significantly promoted the release of the anti-inflammatory cytokine IL-10. ${ }^{77,78}$ In a piroxicam-induced IL-10 $0^{-/}$mouse model, infection with Heligmosomoides polygyrus promoted the production of IL-13 in the intestinal mucosa and inhibited the production of IFN- $\gamma$ and IL-12 p40. Mesenteric lymph node cells in mice infected with Heligmosomoides polygyrus can alleviate pathological damages in the colon. ${ }^{79}$ A clinical experiment showed that CD activity index began to decrease in partial patients when they were infected with Necator americanus 20 weeks later, which may be related to the increasing eosinophils in blood. ${ }^{11}$ Another clinical experiment showed that symptoms were alleviated in $73 \%$ of patients after 24 weeks infection with Trichuris suis ova. Patients treated with immunosuppressive drugs showed a greater degree of improvement. ${ }^{8}$ In addition, helminth-induced Th2-type immune response can increase the production of mucus by intestinal goblet cells, which contributes to the growth of Clostridium bacteria but limits the growth of Bacteroidetes. ${ }^{80}$ Acetate and butyrate produced by the altered gut microbiota can exert anti-inflammatory effects to protect against colitis. ${ }^{81}$ These results show that helminth therapy is a potential therapeutic direction for IBD.

\section{Helminth Therapy for Allergic Asthma}

Helminth infection can reduce the morbidity of allergic asthma. Helminth infection is often accompanied by high levels of $\operatorname{IgE}$ antibodies, and most antibodies are not allergen-specific and enhances tolerance of mast cells to allergens. ${ }^{82}$ In addition, in asymptomatic people with helminth infection, high levels of IgG4 can also inhibit IgEmediated degranulation of effector cells. ${ }^{83}$ Many studies have confirmed that infection with Schistosoma mansoni, Heligmosomoides polygyrus, and Trichinella can alleviate pathological changes caused by allergens, such as airway inflammation and airway hyperresponsiveness. ${ }^{84-86}$ In mice infected with Schistosoma japonicum, DCs can release a large amount of IL-10 that is required for tolerance to alleviate allergic asthma symptoms. When those DCs are adoptively transferred into recipients, the number of $\mathrm{CD} 4^{+} \mathrm{CD} 25^{+} \mathrm{Foxp} 3^{+} \mathrm{T}$ cells and $\mathrm{CD} 4^{+} \mathrm{CD} 25^{+} \mathrm{IL}-10^{+} \mathrm{T}$ cells are increasing and allergic inflammation in the airway is suppressed. ${ }^{87}$ IL-4, IL-13 and IL-10 can induce alternative activation of macrophages to release a large quantity of anti-inflammatory cytokines to limit the inflammatory response. In addition, Heligmosomoides polygyrus or Trichinella spiralis can inhibit the OVA-induced allergic inflammation through Treg cells. ${ }^{88,89}$ Unexpectedly, there were reports that helminth therapy had no obvious effect in the clinical course of allergic asthma. ${ }^{9}$ Infection with Ascaris lumbricoides increases the risk of non-allergic asthma, therefore it is necessary to evaluate the effect of the helminth loads and helminth species on the development of asthma. ${ }^{90}$ This may be because the different compositions of ESPs at various stages of helminth infection exerted variable immune effects. In addition, another possible explanation is that helminth infection must occur prior to the development of allergic asthma, to prevent its development rather than treat it.

\section{The Immunoregulatory Mechanisms of Identified Helminth-Derived Molecules}

Helminth derivative molecules identified so far can be divided into proteins, carbohydrates, lipids, RNA and small organic molecules based on their molecular properties (Table 1). The interaction between identified helminth-derived molecules and target cells generates more stable immune effects than that between ESPs and target cells. The immune responses induced by helminth-derived molecules can be divided into two types: Th2-type immune response and immunosuppression (Figure 4). In mouse models of IBD, these molecules can alleviate the pathological damage in colon, such as the infiltration of inflammatory cells, hyperemia, ulcers, and length of colon. In mouse models of allergic asthma, these molecules can inhibit allergen-induced inflammation in lung, including the infiltration of inflammatory cells around the airway and blood vessels, alveolar wall integrity, the number of eosinophils and OVAspecific IgE. 
Table I Classification of Identified Helminth-Derived Molecules

\begin{tabular}{|c|c|c|c|c|c|c|}
\hline Molecule & Helminth & Source & Immune Cells & Immune Response & Model & Ref \\
\hline \multirow[t]{15}{*}{ Protein } & IPSE/alpha-I & Schistosoma mansoni eggs & Basophils & Th2 immune response & - & [96] \\
\hline & $\begin{array}{l}\text { Thioredoxin } \\
\text { peroxidase-2 }\end{array}$ & Trichinella spiralis & $\begin{array}{l}\text { Macrophage } \rightarrow \text { Th2 } \\
\text { cells }\end{array}$ & Th2 immune response & - & [97] \\
\hline & Omega-I & Schistosoma mansoni eggs & $\mathrm{DC} s \rightarrow \mathrm{Th} 2$ cells & Th2 immune response & - & [102] \\
\hline & Cystatin & Acanthocheilonema viteae & Macrophages & Immunosuppressive response & $\begin{array}{l}\text { Pollen-induced allergic diseases and DSS- } \\
\text { induced colitis }\end{array}$ & {$[114,115]$} \\
\hline & $\begin{array}{l}\text { Helminth defense } \\
\text { molecules }\end{array}$ & Fasciola hepatica & Macrophages & Immunosuppressive response & HDM-induced model of asthma & {$[1 \mid 2,145]$} \\
\hline & Peroxiredoxin & $\begin{array}{l}\text { Schistosoma mansoni and } \\
\text { Fasciola hepatica }\end{array}$ & $\begin{array}{l}\text { Macrophages } \rightarrow \text { Th2 } \\
\text { cells }\end{array}$ & Th2 immune response & - & {$[99,100]$} \\
\hline & Serine protease & Trichinella spiralis & Macrophage & Immunosuppressive response & DSS- induced colitis & [110] \\
\hline & Cystatin & Trichinella spiralis & $\begin{array}{l}\text { Th2 cells and Treg } \\
\text { cells }\end{array}$ & Inhibiting the ThI response & TNBS- induced colitis & [98] \\
\hline & Hemozoin & Opisthorchis felineus & Human DCs & Immunosuppressive response & - & [123] \\
\hline & Cystatin & Ascaris lumbricoides & Treg cells & Immunosuppressive response & $\begin{array}{l}\text { Blomia tropicalis-induced asthma and DSS- } \\
\text { induced colitis }\end{array}$ & {$[124,146]$} \\
\hline & Recombinant Sj16 & Schistosoma japonicum & Treg cells & Immunosuppressive response & DSS- induced colitis & [140] \\
\hline & SJMHEI Peptide & Schistosoma japonicum & Treg cells & Immunosuppressive response & $\begin{array}{l}\text { OVA model of asthma and DSS- induced } \\
\text { colitis }\end{array}$ & {$[137,138]$} \\
\hline & TGF- $\beta$ mimic & Heligmosomoides polygyrus & $\mathrm{CD}^{+} \mathrm{T}$ cells & Immunosuppressive response & Allograft rejection and DSS-induced colitis & {$[128,129]$} \\
\hline & Cathepsin BI protease & Schistosoma mansoni & Macrophages & Inhibiting the THI response & - & [III] \\
\hline & Cystatin & Schistosoma japonicum & Treg cells & Immunosuppressive response & TNBS- induced colitis & [117] \\
\hline
\end{tabular}


Table I (Continued).

\begin{tabular}{|c|c|c|c|c|c|c|}
\hline Molecule & Helminth & Source & Immune Cells & Immune Response & Model & Ref \\
\hline & FheCLI protease & Fasciola hepatica & Macrophages & Inhibiting the THI response & - & {$[111]$} \\
\hline & $\mathrm{Fh} / 2$ & Fasciola hepatica & PBMCs & Immunosuppressive response & - & {$[106,107]$} \\
\hline & Antigen B & Echinococcus granulosus & $\begin{array}{l}\text { Monocyte } \\
\text { precursors }\end{array}$ & Immunosuppressive response & - & [121] \\
\hline & Antigen B & Echinococcus granulosus & iDCs & Th2 immune response & - & {$[12 \mid]$} \\
\hline & $\begin{array}{l}\text { Anti-inflammatory } \\
\text { protein-2 }\end{array}$ & Ancylostoma caninum & $\begin{array}{c}\mathrm{CDIO3}^{+} \mathrm{DCs} \rightarrow \text { Treg } \\
\text { cells }\end{array}$ & Immunosuppressive response & OVA-induced allergic & [126] \\
\hline & Cystatin & Brugia malayi & $\begin{array}{l}\text { Peritoneal } \\
\text { macrophage }\end{array}$ & Immunosuppressive response & DSS-induced colitis & [116] \\
\hline & P43 & Trichuris muris & - & $\begin{array}{l}\text { Inhibiting IL-13-dependent immune } \\
\text { responses }\end{array}$ & - & [139] \\
\hline & Sm200 and SmKI-I & Schistosoma mansoni & Monocytes & Immunosuppressive response & Blomia tropicalis-induced models of asthma & [108] \\
\hline & HPBARI & Heligmosomoides polygyrus & ST2-expressing cells & Immunosuppressive response & Alternaria-OVA induced asthma & [136] \\
\hline & $\begin{array}{l}\text { Serine protease } \\
\text { inhibitor }\end{array}$ & Trichinella spiralis & Macrophages & Immunosuppressive response & TNBS- induced colitis & [109] \\
\hline & $\begin{array}{l}\text { Enzymatically active } \\
\text { chitinase }\end{array}$ & Trichuris suis & Macrophages & Inhibiting the Th2 response & OVA induced asthma & [14I] \\
\hline & HpARI & Heligmosomoides polygyrus & Necrotic cells & Inhibiting the Th2 response & Alternaria-induced allergic & [135] \\
\hline \multirow[t]{2}{*}{ Carbohydrate } & $\begin{array}{l}\text { Lacto-N-fucopentaose } \\
\text { III }\end{array}$ & Schistosoma mansoni & $\mathrm{DC} s \rightarrow \mathrm{Th} 2$ cells & Th2 immune response & - & {$[101]$} \\
\hline & Lewisx & Schistosoma mansoni eggs & DCs & Th2 immune response & - & {$[104,105]$} \\
\hline Lipid & Lysophosphatidylserine & Schistosoma mansoni eggs & $\mathrm{DCs} \rightarrow$ Treg cells & Immunosuppressive response & - & [122] \\
\hline \multirow[t]{2}{*}{ RNA } & miRNAs & $\begin{array}{c}\text { Exosomes of Heligmosomoides } \\
\text { polygyrus }\end{array}$ & - & Immunosuppressive response & Alternaria-induced allergy & [144] \\
\hline & $\begin{array}{l}\text { Double-stranded- } \\
\text { RNAs }\end{array}$ & Schistosoma mansoni eggs & DCs & ThI immune response & - & [147] \\
\hline $\begin{array}{l}\text { Small organic } \\
\text { molecules }\end{array}$ & Succinic acid & Nippostrongylus brasiliensis & $\begin{array}{l}\text { Intestinal tuft cells } \\
\qquad \rightarrow \mathrm{LC} 2\end{array}$ & Th2 immune response & - & [95] \\
\hline
\end{tabular}




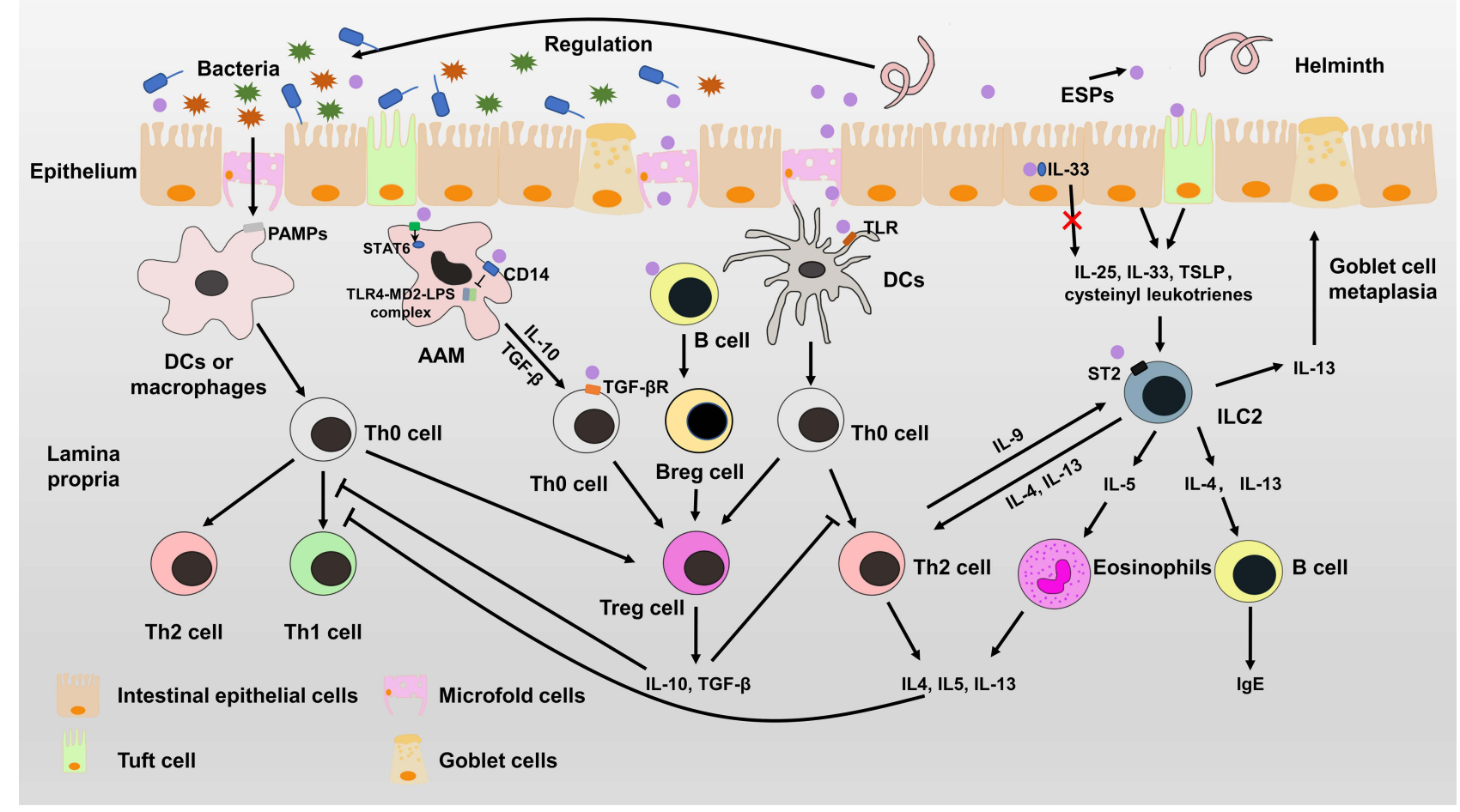

Figure 4 Immunomodulatory mechanisms of helminths. Helminths can induce intestinal epithelial cells to produce IL-25, IL-33 and TSLP, which can stimulate the proliferation of ILC2s. Activated ILC2s can secrete IL-4, IL-5 and IL-I3 to expand Th2-type immune responses, which can suppress the ThI-type immune response. HPARI of Heligmosomoides polygyrus can bind to IL-33 and restrict it in necrotic cells. ESPs can induce the differentiation of Treg cells by interacting with antigen presenting cells or Th0 cells. ESPs not only induces alternative activation of macrophages (AAM) by phosphorylation of STAT6, but also inhibits the pro-inflammatory response mediated by TLR4-MD2-LPS complex. ESPs can affect the function of antigen-presenting cells to induce differentiation of Treg cells or Th2 cells. Treg cells, Breg cells and alternatively activated macrophages can secrete anti-inflammatory cytokines to suppress the Thl-type immune response and Th2-type immune response. In addition, helminths can regulate the diversity and composition of gut microbiota to alter the immune system.

\section{Th2-Type Immune Response Induced by Identified Helminth-Derived Molecules}

The initiation and development of the Th2-type immune response induced by helminths is a complex process involving multiple cells, such as mucosal epithelial cells, ILC2s and CD4 ${ }^{+} \mathrm{T}$ cells. Intestinal tuft cells can be stimulated by ESPs or extracts of Trichinella spiralis to produce IL-25. ${ }^{91}$ IL-25 can stimulate the proliferation of ILC2s in the intestinal mucosa, which releases IL-4, IL-13 and IL-5 with an increase in the number of tuft cells through positive feedback. ${ }^{92}$ Furthermore, intestinal tuft cells secrete cysteinyl leukotrienes during helminth infection, which cooperate with IL-25 to activate ILC2s and expand Th2-type immune response. ${ }^{93}$ Activation of GATA3, STAT6 and other transcription factors related to Th2 differentiation can inhibit Th1 or Th17 differentiation as well as the production of cytokines that drive IBD development, such as IFN- $\gamma$, IL-1 $\beta$, TNF- $\alpha$ and IL-17. ${ }^{94}$

It has been reported that Nippostrongylus brasiliensis can secrete succinic acid, which stimulates the intestinal tuft cell-ILC2 circuit and initiates the early Th2-type immune response. ${ }^{95}$ The glycoprotein IPSE/alpha-1 in Schistosoma mansoni eggs depends on antigen-nonspecific IgE antibodies to induce the production of IL-4 in liver basophils, which also contribute to the early initiation of the Th2-type immune response. ${ }^{96}$ Thioredoxin peroxidase- 2 of Trichinella spiralis can induce alternative activation of macrophages and differentiation of naïve T cells into Th2 cells in vitro. ${ }^{97}$ Cystatin of Trichinella spiralis can inhibit the Th1-type immune response by inducing production of IL-4 and Treg cells in TNBS-induced colitis. ${ }^{98}$ Peroxiredoxin secreted by Schistosoma mansoni or Fasciola hepatica can induce the alternative activation of macrophages and the activation of naive T cells to secrete IL-4, IL-5 and IL-13. ${ }^{99,100}$ Lacto$\mathrm{N}$-fucopentaose III of Schistosoma mansoni can induce the maturation of DCs via ERK/MAPK pathway and promote the differentiation of Th2 cells. ${ }^{101}$ Omega-1, a glycoprotein secreted by Schistosoma mansoni eggs, can activate DCs to induce naïve CD4+ $\mathrm{T}$ cells to differentiate toward $\mathrm{Th} 2$ cells in vitro independent of the IL-4 receptor signaling 
pathway. ${ }^{102}$ Furthermore, C-type lectins are important transmembrane pattern recognition receptors, including C-type lectin dendritic cell-specific ICAM-3-grabbing nonintegrin (DC-sign), macrophage galactose-type lectin and mannose receptor. ${ }^{103}$ There are many glycoconjugates in Schistosoma mansoni eggs, in which the carbohydrate antigen Lewisx can be combined with the DC-sign on the surface of DCs from human peripheral blood mononuclear cells. ${ }^{104}$ The interaction between Lewisx and DC-sign can activate the ERK signaling pathway and contribute to DC maturation, which can induce a Th2-type immune response. ${ }^{105}$

\section{Immunosuppressive Response Induced by Identified Helminth-Derived Molecules}

The immunosuppressive microenvironment induced by helminths can not only facilitate helminths to escape the host's immune response but also prevent the body from severe damage caused by excessive inflammation. Macrophages, DCs, Treg cells, Breg cells and anti-inflammatory cytokines contribute to the formation of an immunosuppressive microenvironment.

Alternatively activated macrophages, members of the innate immune cell family, play an important role in suppressing the immune response. A fatty acid binding protein (Fh12) secreted by Fasciola hepatica induced human peripheral blood mononuclear cells (PBMCs) to express arginase, CHI3L1 and alternatively activated macrophages released antiinflammatory cytokines IL-10. ${ }^{106}$ On the other hand, Fh12 can also target the CD14 receptor on macrophages to prevent the formation of the TLR4-MD2-LPS complex in intracellular inflammatory transduction pathways, which can directly reduce the level of pro-inflammatory cytokines. ${ }^{107} \mathrm{Sm} 200$ and SmKI-1 of Schistosoma mansoni can induce human PBMCs to secrete IL-10 and inhibit the production of inflammatory cytokines in Blomia tropicalis-induced models of asthma. ${ }^{108}$ The serine protease inhibitor secreted by Trichinella spiralis can also induce alternative activation of peritoneal macrophages and bone marrow-derived macrophages in mice, and these alternatively activated macrophages can alleviate pathological changes in the colon caused by TNBS. ${ }^{109}$ Similarly, serine protease from Trichinella spiralis can induce macrophages to produce IL10 to inhibit colitis caused by DSS. ${ }^{110}$ The Fhecl1 protease of Fasciola hepatica and cathepsin B1 protease of Schistosoma mansoni, members of the cysteine protease family, can degrade endosomal TLR3 receptors of macrophages and inhibit TRIFdependent signaling pathways to directly suppress the development of the Th1-type immune response. ${ }^{111}$ In addition, the molecular structure and function of helminth defense molecules in Fasciola hepatica are similar to mammalian antimicrobial peptide host defense peptide. Helminth defense molecules can hinder the antigenic processing and antigen presentation of macrophages to weaken the host immune response. ${ }^{112}$ Cystatin secreted by Acanthocheilonema viteae can induce macrophages to produce a large amount of IL-10, which alleviates pathological damage in the OVA-induced allergic asthma and DSS-induced colitis models in mice. ${ }^{13,114}$ Further studies found that cystatin showed great therapeutic effects in both pollensensitized mice and PBMCs from patients with pollen allergies in vitro, which reveals its potential in the treatment of polleninduced allergic diseases. ${ }^{115}$ Cystatin of Brugia malayi or Schistosoma japonicum can induce alternative activation of peritoneal macrophages and Treg cells to reduce the production of pro-inflammatory cytokines in colon tissue. ${ }^{116-118}$

DCs, professional antigen-presenting cells, are the key component of the immune system connecting innate immunity and adaptive immunity. After uptake and presentation of antigens in peripheral tissues, DCs migrate to lymph nodes to drive the differentiation of naïve $\mathrm{CD}^{+} \mathrm{T}$ cells. Helminths and helminth-derived molecules can regulate the phenotype and function of DCs, including surface markers (MHC class II molecules, CD80, CD86) ${ }^{119}$ and cytokines (IL-12, TGF- $\beta$, IL-10). ${ }^{120}$ It has been reported that antigen B secreted by Echinococcus granulosus can inhibit monocyte precursors from differentiating into immature DCs to weaken the host's immune response. ${ }^{121}$ Lysophosphatidylserine of Schistosoma mansoni eggs, which contains specific acyl chains, can change the function of DCs through TLR2 receptors to induce a large number of IL-10-secreting Treg cells. ${ }^{122}$ In addition, hemozoin of Opisthorchis felineus and cystatin of Ascaris lumbricoides can induce the secretion of IL-10 in human DCs. ${ }^{123,124}$

Treg cells play an important role in maintaining the body's immune tolerance due to secrete the anti-inflammatory cytokines IL-10 and TGF- $\beta$. The number of Treg cells usually increases during helminth infection. ${ }^{125}$ It has been reported that helminths can induce the differentiation of Treg cells through two pathways, one indirect pathway of antigenpresenting cells and the other direct pathway of helminth-derived molecules. Anti-inflammatory protein-2 of Ancylostoma caninum could induce the generation of Treg cells by $\mathrm{CD}_{103}{ }^{+} \mathrm{DCs}$ to prevent or treat asthma symptoms in a mouse model. ${ }^{126}$ The differentiation of Treg cells can be directly induced by helminths that have molecules to 
replicate the biological activity or function of the transforming growth factor superfamily. For example, an activin/TGFlike molecule of Fasciola hepatica has a high affinity for the TGF-RII receptor in bovines. ${ }^{127}$ A Heligmosomoides polygyrus TGF- $\beta$ mimic can directly bind to TGF- $\beta$ receptors in humans and mice, and induce differentiation of Treg cells, which alleviates pathological damage in the allograft rejection and DSS-induced colitis models in mice. ${ }^{128,129}$ Cell therapy using Treg cells to treat allergic asthma has been reported. Adoptive transfer of Treg cells from Trichinella spiralis-infected mice to OVA-treated mice showed significant anti-inflammatory effects. ${ }^{89}$

Breg cells is a subset of B cells that can secrete IL-10 and TGF- $\beta$ to regulate the immune response. Multiple studies have shown that infection with helminths can be accompanied by the proliferation of Breg cells. ${ }^{130-132}$ IL- $10^{+}$Breg cells not only induce expansion of IL- $10^{+}$Treg cells and maintenance of $\mathrm{FoxP}^{+}$Treg cells, but also inhibit inflammatory response in OVA model of asthma. ${ }^{133}$ IPSE/alpha-1 of Schistosoma mansoni can induce Breg cells in mice and humans in vitro. ${ }^{134}$

In addition, HPARI secreted by Heligmosomoides polygyrus can bind to IL-33 and restrict it in necrotic cells, which directly weakens allergic airway inflammation. ${ }^{135} \mathrm{HpBARI}$ of Heligmosomoides polygyrus can bind murine ST2 to prevent IL-33-ST2 interactions, which can suppress BAL and lung eosinophilia in Alternaria-OVA model of asthma. ${ }^{136}$ SJMHE1 Peptide of Schistosoma japonicum can induce proliferation of Treg cells to suppress inflammatory response in OVA-induced model of asthma and DSS-induced model of colitis. ${ }^{137,138}$ P43 of Trichuris muris can inhibit IL-13-dependent immune responses by interacting with IL-13. ${ }^{139}$ Recombinant $\mathrm{Sj} 16$ of Schistosoma japonicum can inhibit DSS-induced inflammation by inhibiting the PPAR- $\alpha$ signaling pathway. ${ }^{140}$ The enzymatically active chitinase of Trichuris suis is similar to mouse chitinase, which can inhibit the recruitment of eosinophils in the lungs and airway hyperresponsiveness. ${ }^{141}$ In recent years, exosomes released by helminths, including miRNAs, RNA and proteins, represent a novel immunomodulatory mechanism. ${ }^{142}$ Exosomes released by Schistosoma mansoni can be internalized by DCs via DC-SIGN, and then augment DCs immune responses. ${ }^{143}$ Heligmosomoides polygyrus-derived miRNAs and Y RNAs can be internalized by mouse cells via exosomes and inhibit the allergic reaction, which provides a new pathway to regulate the host's immune response. ${ }^{144}$

\section{Application of Helminth-Derived Molecules}

How to appropriately harness immunoregulation by helminth-derived molecules for the treatment of epidemic IMIDs is still a difficult problem to be solved. Helminth-derived molecules are a class of heterologous antigens, which can not only regulate the immune response, but also interact with the immune system to produce side effects by virtue of their antigenicity. Therefore, it is necessary to assess the interaction between the antigen and the immune system to avoid serious side effects. In addition, with the aggravation of the disease, the immune imbalance is also constantly changing. For example, allergic asthma is triggered by the Th2-type immune response. When the symptoms are aggravated, Th1type immune responses and Th17-type immune responses also contribute to serious pathological damage to tissues and organs. Therefore, it is necessary to assess immune indexes, such as serum cytokines, tissue cytokines, and clinical symptoms. The well-timed application of helminth-derived molecules in response to the changes in immune indexes may be a new direction of helminth therapy in the future.

\section{Conclusion}

IBD and allergic asthma are a group of heterogeneous diseases caused by immune imbalance. Helminths or helminthderived molecules have potential therapeutic value due to the immunomodulatory ability. It is important that identified helminth-derived molecules can induce more stable and controlled immune response to correct the immune balance, including Th2-type immune response and immunosuppressive response. To date, many helminth-derived molecules have shown obvious therapeutic effects in animal models, which provides data to support clinical experiments. The future of helminth-derived molecules in the treatment of IMIDs looks bright.

\section{Abbreviations}

IMIDs, immune-mediated inflammatory diseases; IBD, inflammatory bowel disease; Th1 cells, T helper type 1 cells; Th2 cells, T helper type 2 cells; Th17 cells, T helper type 17 cells; Tfh cells, T follicular helper cells; Breg cells, B regulatory cells; Treg cells, T regulatory cells; ESPs, excretory-secretory products; Nod2, nucleotide-binding oligomerization domain 2; CARD9, caspase recruitment domain family member 9; IL-23R, interleukin-23 receptor; PTPN2, protein 
tyrosine phosphatase non-receptor type 2; NF- $\mathrm{kB}$, the nuclear factor kappa-light-chain-enhancer of activated B cells; OX40L, tumor necrosis factor receptor superfamily member 4 ligand; TSLPR, thymic stromal lymphopoietin receptor; IL-12, interleukin 12; IFN- $\gamma$, interferon-gamma; TNF, tumor necrosis factor; DCs, dendritic cells; OVA, ovalbumin; TNBS, trinitrobenzene sulfonic acid; DNBS, dinitrobenzene sulfonic acid; DSS, dextran sulfate sodium salt; ILC2s, group 2 innate lymphoid cells; DC-sign, C-type lectin dendritic cell-specific ICAM-3-grabbing nonintegrin; PBMCs, peripheral blood mononuclear cells.

\section{Consent for Publication}

All the authors read the manuscript carefully and gave their consent for publication.

\section{Acknowledgments}

The authors sincerely thank Bin Tang and Yan Liu for their critical suggestions on the figures. Wenjie Shi and Ning Xu are co-first authors for this study.

\section{Author Contributions}

All authors made a significant contribution to the work reported, whether that is in the conception, study design, execution, acquisition of data, analysis and interpretation, or in all these areas; took part in drafting, revising or critically reviewing the article; gave final approval of the version to be published; have agreed on the journal to which the article has been submitted; and agree to be accountable for all aspects of the work.

\section{Funding}

This study was supported by the National Key Research and Development Program of China (2021YFC2600202; 2017YFC1601200); the National Natural Science Foundation of China (NO. NSFC31872467); the China Postdoctoral Science Foundation (2021M701395) and Program for JLU Science and Technology Innovative Research Team (2017TD$32)$.

\section{Disclosure}

The authors report no conflicts of interest in this work.

\section{References}

1. Ryan SM, Eichenberger RM, Ruscher R, et al. Harnessing helminth-driven immunoregulation in the search for novel therapeutic modalities. PLoS Pathog. 2020;16:e1008508. doi:10.1371/journal.ppat.1008508

2. Weinstock JV, Elliott DE. Helminth infections decrease host susceptibility to immune-mediated diseases. J Immunol. 2014;193:3239-3247. doi:10.4049/jimmunol.1400927

3. Weinstock JV, Elliott DE. Helminths and the IBD hygiene hypothesis. Inflamm Bowel Dis. 2009;15:128-133. doi:10.1002/ibd.20633

4. Rook GAW. 99th Dahlem Conference on infection, inflammation and chronic inflammatory disorders: Darwinian medicine and the 'hygiene' or 'old friends' hypothesis. Clin Exp Immunol. 2010;160:70-79. doi:10.1111/j.1365-2249.2010.04133.x

5. Hirahara K, Nakayama T. CD4+ T-cell subsets in inflammatory diseases: beyond the Th1/Th2 paradigm. Int Immunol. 2016;28:163-171. doi:10.1093/intimm/dxw006

6. Metenou S, Dembele B, Konate S, et al. At homeostasis filarial infections have expanded adaptive T regulatory but not classical Th2 cells. J Immunol. 2010;184:5375-5382. doi:10.4049/jimmunol.0904067

7. Heylen M, Ruyssers NE, Gielis EM, et al. Of worms, mice and man: an overview of experimental and clinical helminth-based therapy for inflammatory bowel disease. Pharmacol Ther. 2014;143:153-167. doi:10.1016/j.pharmthera.2014.02.011

8. Summers RW, Elliott DE, Urban JF, et al. Trichuris suis therapy in Crohn's disease. Gut. 2005;54:87-90. doi:10.1136/gut.2004.041749

9. Bager P, Arnved J, Ronborg S, et al. Trichuris suis ova therapy for allergic rhinitis: a randomized, double-blind, placebo-controlled clinical trial. J Allergy Clin Immunol. 2010;125:123-130 e121-123. doi:10.1016/j.jaci.2009.08.006

10. Bourke CD, Mutapi F, Nausch N, et al. Trichuris suis ova therapy for allergic rhinitis does not affect allergen-specific cytokine responses despite a parasite-specific cytokine response. Clin Exp Allergy. 2012;42:1582-1595. doi:10.1111/j.1365-2222.2012.04063.x

11. Croese J, O'Neil J, Masson J, et al. A proof of concept study establishing Necator americanus in Crohn's patients and reservoir donors. Gut. 2006;55:136-137. doi:10.1136/gut.2005.079129

12. Kahl J, Brattig N, Liebau E. The untapped pharmacopeic potential of helminths. Trends Parasitol. 2018;34:828-842. doi:10.1016/j. pt.2018.05.011 
13. Maruszewska-Cheruiyot M, Szewczak L, Krawczak-Wojcik K, et al. The production of excretory-secretory molecules from Heligmosomoides polygyrus bakeri fourth stage larvae varies between mixed and single sex cultures. Parasite Vector. $2021 ; 14$. doi:10.1186/s13071-021-04613-9

14. Logan J, Pearson MS, Manda SS, et al. Comprehensive analysis of the secreted proteome of adult Necator americanus hookworms. PLoS Negl Trop Dis. 2020;14:e0008237. doi:10.1371/journal.pntd.0008237

15. Namara B, Nash S, Lule SA, et al. Effects of treating helminths during pregnancy and early childhood on risk of allergy-related outcomes: follow-up of a randomized controlled trial. Pediat Allerg Imm. 2017;28:784-792. doi:10.1111/pai.12804

16. Park JH, Peyrin-Biroulet L, Eisenhut M, et al. IBD immunopathogenesis: a comprehensive review of inflammatory molecules. Autoimmun Rev. 2017;16:416-426. doi:10.1016/j.autrev.2017.02.013

17. Na SY, Moon W. Perspectives on current and novel treatments for inflammatory bowel disease. Gut Liver. 2019;13:604-616. doi:10.5009/ gnl19019

18. Joossens M, Simoens M, Vermeire S, et al. Contribution of genetic and environmental factors in the pathogenesis of Crohn's disease in a large family with multiple cases. Inflamm Bowel Dis. 2007;13:580-584. doi:10.1002/ibd.20086

19. Ananthakrishnan AN. Epidemiology and risk factors for IBD. Nat Rev Gastroenterol Hepatol. 2015;12:205-217. doi:10.1038/nrgastro.2015.34

20. Zhao M, Feng R, Ben-Horin S, et al. Systematic review with meta-analysis: environmental and dietary differences of inflammatory bowel disease in Eastern and Western populations. Aliment Pharmacol Ther. 2021. doi:10.1111/apt.16703

21. Cui GL, Liu HZ, Xu G, et al. Exploring links between industrialization, urbanization, and Chinese inflammatory bowel disease. Front Med. 2021;8:2047.

22. Khor B, Gardet A, Xavier RJ. Genetics and pathogenesis of inflammatory bowel disease. Nature. 2011;474:307-317. doi:10.1038/nature10209

23. Glocker EO, Kotlarz D, Boztug K, et al. Inflammatory bowel disease and mutations affecting the interleukin-10 receptor. $N$ Engl J Med. 2009;361:2033-2045. doi:10.1056/NEJMoa0907206

24. Liu TC, Stappenbeck TS. Genetics and pathogenesis of inflammatory bowel disease. Annu Rev Pathol. 2016;11:127-148. doi:10.1146/annurevpathol-012615-044152

25. Lauro ML, Burch JM, Grimes CL. The effect of NOD2 on the microbiota in Crohn's disease. Curr Opin Biotechnol. 2016;40:97-102. doi:10.1016/j.copbio.2016.02.028

26. Yang E, Shen J. The roles and functions of Paneth cells in Crohn's disease: a critical review. Cell Prolif. 2021;54:e12958. doi:10.1111/cpr.12958

27. Gubatan J, Holman DR, Puntasecca CJ, et al. Antimicrobial peptides and the gut microbiome in inflammatory bowel disease. World $J$ Gastroenterol. 2021;27:7402-7422. doi:10.3748/wjg.v27.i43.7402

28. Magalhaes JG, Rubino SJ, Travassos LH, et al. Nucleotide oligomerization domain-containing proteins instruct T cell helper type 2 immunity through stromal activation. Proc Natl Acad Sci U S A. 2011;108:14896-14901. doi:10.1073/pnas.1015063108

29. Glassner KL, Abraham BP, Quigley EMM. The microbiome and inflammatory bowel disease. J Allergy Clin Immunol. 2020;145:16-27. doi:10.1016/j.jaci.2019.11.003

30. Bouma G, Strober W. The immunological and genetic basis of inflammatory bowel disease. Nat Rev Immunol. 2003;3:521-533. doi:10.1038/ nri1132

31. Qu J, Liu L, Xu Q, et al. CARD9 prevents lung cancer development by suppressing the expansion of myeloid-derived suppressor cells and IDO production. Int $J$ Cancer. 2019;145:2225-2237. doi:10.1002/ijc.32355

32. Strasser D, Neumann K, Bergmann H, et al. Syk kinase-coupled C-type lectin receptors engage protein kinase C-delta to elicit Card9 adaptor-mediated innate immunity. Immunity. 2012;36:32-42. doi:10.1016/j.immuni.2011.11.015

33. Cao Z, Conway KL, Heath RJ, et al. Ubiquitin ligase TRIM62 regulates CARD9-mediated anti-fungal immunity and intestinal inflammation. Immunity. 2015;43:715-726. doi:10.1016/j.immuni.2015.10.005

34. Goel S, Kuehn HS, Chinen J, et al. CARD9 expression pattern, gene dosage, and immunodeficiency phenotype revisited. J Clin Immunol. 2021. doi:10.1007/s10875-021-01173-6

35. Luo P, Yang Z, Chen B, et al. The multifaceted role of CARD9 in inflammatory bowel disease. J Cell Mol Med. 2020;24:34-39. doi:10.1111/ jcmm. 14770

36. Neurath MF. IL-23 in inflammatory bowel diseases and colon cancer. Cytokine Growth Factor Rev. 2019;45:1-8. doi:10.1016/j. cytogfr.2018.12.002

37. Spalinger MR, Sayoc-Becerra A, Santos AN, et al. PTPN2 regulates interactions between macrophages and intestinal epithelial cells to promote intestinal barrier function. Gastroenterology. 2020;159:1763-+. doi:10.1053/j.gastro.2020.07.004

38. Garcia-Carbonell R, Wong J, Kim JY, et al. Elevated A20 promotes TNF-induced and RIPK1-dependent intestinal epithelial cell death. Proc Natl Acad Sci U S A. 2018;115:E9192-E9200. doi:10.1073/pnas.1810584115

39. Wallace JW, Constant DA, Nice TJ. Interferon lambda in the pathogenesis of inflammatory bowel diseases. Front Immunol. 2021;12:767505. doi:10.3389/fimmu.2021.767505

40. Farache J, Koren I, Milo I, et al. Luminal bacteria recruit CD103+ dendritic cells into the intestinal epithelium to sample bacterial antigens for presentation. Immunity. 2013;38:581-595. doi:10.1016/j.immuni.2013.01.009

41. Schirmer M, Franzosa EA, Lloyd-Price J, et al. Dynamics of metatranscription in the inflammatory bowel disease gut microbiome. Nat Microbiol. 2018;3:337-346. doi:10.1038/s41564-017-0089-z

42. Imhann F, Vich Vila A, Bonder MJ, et al. Interplay of host genetics and gut microbiota underlying the onset and clinical presentation of inflammatory bowel disease. Gut. 2018;67:108-119. doi:10.1136/gutjnl-2016-312135

43. Lupp C, Robertson ML, Wickham ME, et al. Host-mediated inflammation disrupts the intestinal microbiota and promotes the overgrowth of Enterobacteriaceae. Cell Host Microbe. 2007;2:204. doi:10.1016/j.chom.2007.08.002

44. Furusawa Y, Obata Y, Fukuda S, et al. Commensal microbe-derived butyrate induces the differentiation of colonic regulatory T cells. Nature. 2013;504:446-450. doi:10.1038/nature12721

45. Levine A, Wine E, Assa A, et al. Crohn's disease exclusion diet plus partial enteral nutrition induces sustained remission in a randomized controlled trial. Gastroenterology. 2019;157:440-450 e448. doi:10.1053/j.gastro.2019.04.021

46. Doherty G, Katsanos KH, Burisch J, et al. European Crohn's and colitis organisation topical review on treatment withdrawal ['exit strategies'] in inflammatory bowel disease. $J$ Crohns Colitis. 2018;12:17-31. doi:10.1093/ecco-jcc/jjx101 
47. Brown G. 5-aminosalicylic acid-associated myocarditis and pericarditis: a narrative review. Can J Hosp Pharm. 2016;69:466-472.

48. Bonovas S, Fiorino G, Allocca M, et al. Biologic therapies and risk of infection and malignancy in patients with inflammatory bowel disease: a systematic review and network meta-analysis. Clin Gastroenterol Hepatol. 2016;14:1385-1397 e1310. doi:10.1016/j.cgh.2016.04.039

49. Papi A, Brightling C, Pedersen SE, et al. Asthma. Lancet. 2018;391:783-800. doi:10.1016/S0140-6736(17)33311-1

50. Vasileiadou S, Ekerljung L, Bjerg A, et al. Asthma increased in young adults from 2008-2016 despite stable allergic rhinitis and reduced smoking. PLoS One. 2021;16:e253322. doi:10.1371/journal.pone.0253322

51. Zhang Y, Zhang L. Increasing prevalence of allergic rhinitis in China. Allergy Asthma Immunol Res. 2019;11:156-169. doi:10.4168/ aair.2019.11.2.156

52. Paaso EM, Jaakkola MS, Rantala AK, et al. Allergic diseases and asthma in the family predict the persistence and onset-age of asthma: a prospective cohort study. Respir Res. 2014;15:152. doi:10.1186/s12931-014-0152-8

53. Mukherjee AB, Zhang Z. Allergic asthma: influence of genetic and environmental factors. J Biol Chem. 2011;286:32883-32889. doi:10.1074/ jbc.R110.197046

54. Chan BCL, Lam CWK, Tam LS, et al. IL33: roles in allergic inflammation and therapeutic perspectives. Front Immunol. $2019 ; 10: 364$. doi:10.3389/fimmu.2019.00364

55. Boberg E, Johansson K, Malmhall C, et al. House dust mite induces bone marrow IL-33-responsive ILC2s and TH cells. Int J Mol Sci. 2020;21:3751. doi:10.3390/ijms21113751

56. Kelsen SG, Agache IO, Soong W, et al. Astegolimab (anti-ST2) efficacy and safety in adults with severe asthma: a randomized clinical trial. J Allergy Clin Immunol. 2021;148:790-798. doi:10.1016/j.jaci.2021.03.044

57. Ege MJ, Mayer M, Normand AC, et al. Exposure to environmental microorganisms and childhood asthma. $N$ Engl J Med. 2011;364:701-709. doi:10.1056/NEJMoa1007302

58. Murrison LB, Brandt EB, Myers JB, et al. Environmental exposures and mechanisms in allergy and asthma development. $J$ Clin Invest. 2019;129:1504-1515. doi:10.1172/JCI124612

59. Hong H, Liao S, Chen F, et al. Role of IL-25, IL-33, and TSLP in triggering united airway diseases toward type 2 inflammation. Allergy. 2020;75:2794-2804. doi:10.1111/all.14526

60. Varricchi G, Harker J, Borriello F, et al. T follicular helper (Tfh) cells in normal immune responses and in allergic disorders. Allergy. 2016;71:1086-1094. doi:10.1111/all.12878

61. Nussbaum JC, Van Dyken SJ, von Moltke J, et al. Type 2 innate lymphoid cells control eosinophil homeostasis. Nature. 2013;502:245-248. doi:10.1038/nature12526

62. Chesne J, Braza F, Mahay G, et al. IL-17 in severe asthma. Where do we stand? Am J Respir Crit Care Med. 2014;190:1094-1101. doi:10.1164/ rccm.201405-0859PP

63. Ventura I, Vega A, Chacon P, et al. Neutrophils from allergic asthmatic patients produce and release metalloproteinase-9 upon direct exposure to allergens. Allergy. 2014;69:898-905. doi:10.1111/all.12414

64. Giovannini-Chami L, Marcet B, Moreilhon C, et al. Distinct epithelial gene expression phenotypes in childhood respiratory allergy. Eur Respir J. 2012;39:1197-1205. doi:10.1183/09031936.00070511

65. Cho SH, Stanciu LA, Holgate ST, et al. Increased interleukin-4, interleukin-5, and interferon-gamma in airway CD4+ and CD8+ T cells in atopic asthma. Am J Respir Crit Care Med. 2005;171:224-230. doi:10.1164/rccm.200310-1416OC

66. Magnan AO, Mely LG, Camilla CA, et al. Assessment of the Th1/Th2 paradigm in whole blood in atopy and asthma. Increased IFN-gammaproducing CD8(+) T cells in asthma. Am J Respir Crit Care Med. 2000;161:1790-1796. doi:10.1164/ajrccm.161.6.9906130

67. Tian D, Yang L, Wang S, et al. Double negative T cells mediate Lag3-dependent antigen-specific protection in allergic asthma. Nat Commun. 2019;10:4246. doi:10.1038/s41467-019-12243-0

68. Pfaar O, Bousquet J, Durham SR, et al. One hundred and ten years of allergen immunotherapy: a journey from empiric observation to evidence. Allergy. 2021. doi:10.1111/all.15023

69. Azam MB, Chhabra S, Agrawal S, et al. A 37-year-old man with bronchial asthma and unexplained hypoxemia. Chest. $2021 ; 160$ :e633-e638. doi:10.1016/j.chest.2021.07.052

70. McGregor MC, Krings JG, Nair P, et al. Role of biologics in asthma. Am J Respir Crit Care Med. 2019;199:433-445. doi:10.1164/ rccm.201810-1944CI

71. Oray M, Abu Samra K, Ebrahimiadib N, et al. Long-term side effects of glucocorticoids. Expert Opin Drug Saf. 2016;15:457-465. doi:10.1517/ 14740338.2016.1140743

72. Orons PD, Amesur NB, Dauber JH, et al. Balloon dilation and endobronchial stent placement for bronchial strictures after lung transplantation. J Vasc Interv Radiol. 2000;11:89-99. doi:10.1016/S1051-0443(07)61288-3

73. Gong T, Liu L, Jiang W, et al. DAMP-sensing receptors in sterile inflammation and inflammatory diseases. Nat Rev Immunol. 2020;20:95-112. doi:10.1038/s41577-019-0215-7

74. Oh SY, Cho KA, Kang JL, et al. Comparison of experimental mouse models of inflammatory bowel disease. Int J Mol Med. 2014;33:333-340. doi:10.3892/ijmm.2013.1569

75. Elliott DE, Li J, Blum A, et al. Exposure to schistosome eggs protects mice from TNBS-induced colitis. Am J Physiol Gastrointest Liver Physiol. 2003;284:G385-391. doi:10.1152/ajpgi.00049.2002

76. Xu J, Yu P, Wu L, et al. Effect of Trichinella spiralis intervention on TNBS-induced experimental colitis in mice. Immunobiology. 2019;224:147-153. doi:10.1016/j.imbio.2018.09.005

77. Hasby EA, Hasby Saad MA, Shohieb Z, et al. FoxP3+ T regulatory cells and immunomodulation after Schistosoma mansoni egg antigen immunization in experimental model of inflammatory bowel disease. Cell Immunol. 2015;295:67-76. doi:10.1016/j.cellimm.2015.02.013

78. Ferreira I, Smyth D, Gaze S, et al. Hookworm excretory/secretory products induce interleukin-4 (IL-4)+ IL-10+ CD4+ T cell responses and suppress pathology in a mouse model of colitis. Infect Immun. 2013;81:2104-2111. doi:10.1128/IAI.00563-12

79. Elliott DE, Setiawan T, Metwali A, et al. Heligmosomoides polygyrus inhibits established colitis in IL-10-deficient mice. Eur J Immunol. 2004;34:2690-2698. doi:10.1002/eji.200324833

80. Ramanan D, Bowcutt R, Lee SC, et al. Helminth infection promotes colonization resistance via type 2 immunity. Science. $2016 ; 352: 608-612$. doi:10.1126/science.aaf3229 
81. Shute A, Callejas BE, Li SH, et al. Cooperation between host immunity and the gut bacteria is essential for helminth-evoked suppression of colitis. Microbiome. 2021;9. doi:10.1186/s40168-021-01146-2

82. Hamid F, Amoah AS, van Ree R, et al. Helminth-induced IgE and protection against allergic disorders. Curr Top Microbiol Immunol. 2015;388:91-108. doi:10.1007/978-3-319-13725-4_5

83. Adjobimey T, Hoerauf A. Induction of immunoglobulin G4 in human filariasis: an indicator of immunoregulation. Ann Trop Med Parasitol. 2010;104:455-464. doi:10.1179/136485910X12786389891407

84. Kang SA, Park MK, Cho MK, et al. Parasitic nematode-induced CD4+Foxp3+T cells can ameliorate allergic airway inflammation. PLoS Negl Trop Dis. 2014;8:e3410. doi:10.1371/journal.pntd.0003410

85. Layland LE, Straubinger K, Ritter M, et al. Schistosoma mansoni-mediated suppression of allergic airway inflammation requires patency and Foxp3+ Treg cells. PLoS Negl Trop Dis. 2013;7:e2379. doi:10.1371/journal.pntd.0002379

86. Hartmann S, Schnoeller C, Dahten A, et al. Gastrointestinal nematode infection interferes with experimental allergic airway inflammation but not atopic dermatitis. Clin Exp Allergy. 2009;39:1585-1596. doi:10.1111/j.1365-2222.2009.03290.x

87. Liu JY, Li LY, Yang XZ, et al. Adoptive transfer of dendritic cells isolated from helminth-infected mice enhanced T regulatory cell responses in airway allergic inflammation. Parasite Immunol. 2011;33:525-534. doi:10.1111/j.1365-3024.2011.01308.x

88. Kitagaki K, Businga TR, Racila D, et al. Intestinal helminths protect in a murine model of asthma. J Immunol. 2006;177:1628-1635. doi:10.4049/jimmunol.177.3.1628

89. Aranzamendi C, de Bruin A, Kuiper R, et al. Protection against allergic airway inflammation during the chronic and acute phases of Trichinella spiralis infection. Clin Exp Allergy. 2013;43:103-115. doi:10.1111/cea.12042

90. Mohammadzadeh I, Rostami A, Darvish S, et al. Exposure to Ascaris lumbricoides infection and risk of childhood asthma in north of Iran. Infection. 2019;47:991-999. doi:10.1007/s15010-019-01343-0

91. Luo XC, Chen ZH, Xue JB, et al. Infection by the parasitic helminth Trichinella spiralis activates a Tas2r-mediated signaling pathway in intestinal tuft cells. Proc Natl Acad Sci U S A. 2019;116:5564-5569. doi:10.1073/pnas.1812901116

92. von Moltke J, Ji M, Liang HE, et al. Tuft-cell-derived IL-25 regulates an intestinal ILC2-epithelial response circuit. Nature. 2016;529:221-225. doi:10.1038/nature16161

93. McGinty JW, Ting HA, Billipp TE, et al. Tuft-cell-derived leukotrienes drive rapid anti-helminth immunity in the small intestine but are dispensable for anti-protist immunity. Immunity. 2020;52:528-541 e527. doi:10.1016/j.immuni.2020.02.005

94. Luo X, Villablanca EJ. Type 2 immunity in intestinal homeostasis and inflammatory bowel disease. Biochem Soc Trans. 2021;49:2371-2380 doi:10.1042/BST20210535

95. Nadjsombati MS, McGinty JW, Lyons-Cohen MR, et al. Detection of succinate by intestinal tuft cells triggers a type 2 innate immune circuit. Immunity. 2018;49:33-41 e37. doi:10.1016/j.immuni.2018.06.016

96. Knuhr K, Langhans K, Nyenhuis S, et al. Schistosoma mansoni egg-released IPSE/alpha-1 dampens inflammatory cytokine responses via basophil interleukin (IL)-4 and IL-13. Front Immunol. 2018;9:2293. doi:10.3389/fimmu.2018.02293

97. Jin QW, Zhang NZ, Li WH, et al. Trichinella spiralis thioredoxin peroxidase 2 regulates protective Th2 immune response in mice by directly inducing alternatively activated macrophages. Front Immunol. 2020;11:2015. doi:10.3389/fimmu.2020.02015

98. Xu J, Liu M, Yu P, et al. Effect of recombinant Trichinella spiralis cysteine proteinase inhibitor on TNBS-induced experimental inflammatory bowel disease in mice. Int Immunopharmacol. 2019;66:28-40. doi:10.1016/j.intimp.2018.10.043

99. Carson JP, Gobert GN. Modulation of the host immune response by schistosome egg-secreted proteins is a critical avenue of host-parasite communication. Pathogens. 2021;10:863. doi:10.3390/pathogens10070863

100. Donnelly S, Stack CM, O'Neill SM, et al. Helminth 2-Cys peroxiredoxin drives Th2 responses through a mechanism involving alternatively activated macrophages. FASEB J. 2008;22:4022-4032. doi:10.1096/fj.08-106278

101. Pearce EJ, Sun J, Sun J, et al. Th2 response polarization during infection with the helminth parasite Schistosoma mansoni. Immunol Rev. 2004;201:117-126. doi:10.1111/j.0105-2896.2004.00187.x

102. Everts B, Perona-Wright G, Smits HH, et al. Omega-1, a glycoprotein secreted by Schistosoma mansoni eggs, drives Th2 responses. $J$ Exp Med. 2009;206:1673-1680. doi:10.1084/jem.20082460

103. Valverde P, Martinez JD, Canada FJ, et al. Molecular recognition in C-type lectins: the cases of DC-SIGN, langerin, MGL, and L-sectin Chembiochem. 2020;21:2999-3025. doi:10.1002/cbic.202000238

104. van Die I, van Vliet SJ, Nyame AK, et al. The dendritic cell-specific C-type lectin DC-SIGN is a receptor for Schistosoma mansoni egg antigens and recognizes the glycan antigen Lewis x. Glycobiology. 2003;13:471-478. doi:10.1093/glycob/cwg052

105. van Liempt E, van Vliet SJ, Engering A, et al. Schistosoma mansoni soluble egg antigens are internalized by human dendritic cells through multiple C-type lectins and suppress TLR-induced dendritic cell activation. Mol Immunol. 2007;44:2605-2615. doi:10.1016/j. molimm.2006.12.012

106. Figueroa-Santiago O, Espino AM, Appleton JA. Fasciola hepatica fatty acid binding protein induces the alternative activation of human macrophages. Infect Immun. 2014;82:5005-5012. doi:10.1128/IAI.02541-14

107. Martin I, Caban-Hernandez K, Figueroa-Santiago O, et al. Fasciola hepatica fatty acid binding protein inhibits TLR4 activation and suppresses the inflammatory cytokines induced by lipopolysaccharide in vitro and in vivo. J Immunol. 2015;194:3924-3936. doi:10.4049/ jimmunol.1401182

108. Alves CL, Santiago LF, Santana MB, et al.Immunomodulatory properties of Schistosoma mansoni proteins Sm200 and SmKI-1 in vitro and in a murine model of allergy to the mite Blomia tropicalis. Mol Immunol. 2020;124:91-99. doi:10.1016/j.molimm.2020.05.011

109. Xu N, Bai X, Liu Y, et al. The anti-inflammatory immune response in early Trichinella spiralis intestinal infection depends on serine protease inhibitor-mediated alternative activation of macrophages. J Immunol. 2021;206:963-977. doi:10.4049/jimmunol.2000290

110. Long SR, Liu RD, Kumar DV, et al. Immune protection of a helminth protein in the DSS-induced colitis model in mice. Front Immunol. 2021;12:664998. doi:10.3389/fimmu.2021.664998

111. Donnelly S, O'Neill SM, Stack CM, et al. Helminth cysteine proteases inhibit TRIF-dependent activation of macrophages via degradation of TLR3. J Biol Chem. 2010;285:3383-3392. doi:10.1074/jbc.M109.060368

112. Robinson MW, Alvarado R, To J, et al. A helminth cathelicidin-like protein suppresses antigen processing and presentation in macrophages via inhibition of lysosomal vATPase. FASEB J. 2012;26:4614-4627. doi:10.1096/fj.12-213876 
113. Hartmann S, Kyewski B, Sonnenburg B, et al. A filarial cysteine protease inhibitor down-regulates $\mathrm{T}$ cell proliferation and enhances interleukin-10 production. Eur J Immunol. 1997;27:2253-2260. doi:10.1002/eji.1830270920

114. Schnoeller C, Rausch S, Pillai S, et al. A helminth immunomodulator reduces allergic and inflammatory responses by induction of IL-10producing macrophages. J Immunol. 2008;180:4265-4272. doi:10.4049/jimmunol.180.6.4265

115. Danilowicz-Luebert E, Steinfelder S, Kuhl AA, et al. A nematode immunomodulator suppresses grass pollen-specific allergic responses by controlling excessive Th2 inflammation. Int J Parasitol. 2013;43:201-210. doi:10.1016/j.ijpara.2012.10.014

116. Bisht N, Khatri V, Chauhan N, et al. Cystatin from Filarial parasites suppress the clinical symptoms and pathology of experimentally induced colitis in mice by inducing T-regulatory cells, B1-cells, and alternatively activated macrophages. Biomedicines. 2019;7:85. doi:10.3390/ biomedicines7040085

117. Wang S, Xie Y, Yang X, et al. Therapeutic potential of recombinant cystatin from Schistosoma japonicum in TNBS-induced experimental colitis of mice. Parasit Vectors. 2016;9:6. doi:10.1186/s13071-015-1288-1

118. Khatri V, Chauhan N, Kalyanasundaram R. Parasite cystatin: immunomodulatory molecule with therapeutic activity against immune mediated disorders. Pathogens. 2020;9:431. doi:10.3390/pathogens9060431

119. Sun XM, Guo K, Hao CY, et al. Trichinella spiralis excretory-secretory products stimulate host regulatory $\mathrm{T}$ cell differentiation through activating dendritic cells. Cells-Basel. 2019;8:1404.

120. Cvetkovic J, Ilic N, Gruden-Movsesijan A, et al. DC-SIGN signalling induced by Trichinella spiralis products contributes to the tolerogenic signatures of human dendritic cells. Sci Rep. 2020;10:20283. doi:10.1038/s41598-020-77497-x

121. Rigano R, Buttari B, Profumo E, et al. Echinococcus granulosus antigen B impairs human dendritic cell differentiation and polarizes immature dendritic cell maturation towards a Th2 cell response. Infect Immun. 2007;75:1667-1678. doi:10.1128/IAI.01156-06

122. van der Kleij D, Latz E, Brouwers JF, et al. A novel host-parasite lipid cross-talk. Schistosomal lyso-phosphatidylserine activates toll-like receptor 2 and affects immune polarization. $J$ Biol Chem. 2002;277:48122-48129. doi:10.1074/jbc.M206941200

123. Saltykova IV, Ittiprasert W, Nevskaya KV, et al. Hemozoin from the liver fluke, Opisthorchis felineus, modulates dendritic cell responses in bronchial asthma patients. Front Vet Sci. 2019;6:332. doi:10.3389/fvets.2019.00332

124. Coronado S, Zakzuk J, Regino R, et al. Ascaris lumbricoides cystatin prevents development of allergic airway inflammation in a mouse model. Front Immunol. 2019;10:2280. doi:10.3389/fimmu.2019.02280

125. Bouchery T, Kyle R, Ronchese F, et al. The differentiation of CD4(+) T-helper cell subsets in the context of helminth parasite infection. Front Immunol. 2014;5:487. doi:10.3389/fimmu.2014.00487

126. Navarro S, Pickering DA, Ferreira IB, et al. Hookworm recombinant protein promotes regulatory T cell responses that suppress experimental asthma. Sci Transl Med. 2016;8. doi:10.1126/scitranslmed.aaf8807

127. Sulaiman AA, Zolnierczyk K, Japa O, et al. A trematode parasite derived growth factor binds and exerts influences on host immune functions via host cytokine receptor complexes. PLoS Pathog. 2016;12:e1005991. doi:10.1371/journal.ppat.1005991

128. Johnston CJC, Smyth DJ, Kodali RB, et al. A structurally distinct TGF-beta mimic from an intestinal helminth parasite potently induces regulatory T cells. Nat Commun. 2017;8:1741. doi:10.1038/s41467-017-01886-6

129. Smyth DJ, Ren B, White MPJ, et al. Oral delivery of a functional algal-expressed TGF-beta mimic halts colitis in a murine DSS model. J Biotechnol. 2021;340:1-12. doi:10.1016/j.jbiotec.2021.08.006

130. Xie J, Shi CW, Huang HB, et al. Induction of the IL-10-producing regulatory B cell phenotype following Trichinella spiralis infection. Mol Immunol. 2021;133:86-94. doi:10.1016/j.molimm.2021.02.012

131. Li M, Wang H, Ni Y, et al. Helminth-induced CD9(+) B-cell subset alleviates obesity-associated inflammation via IL-10 production. Int J Parasitol. 2021. doi:10.1016/j.ijpara.2021.08.009

132. van der Vlugt L, Obieglo K, Ozir-Fazalalikhan A, et al. Schistosome-induced pulmonary B cells inhibit allergic airway inflammation and display a reduced Th2-driving function. Int J Parasitol. 2017;47:545-554. doi:10.1016/j.ijpara.2017.02.002

133. Gao X, Ren X, Wang Q, et al. Critical roles of regulatory B and T cells in helminth parasite-induced protection against allergic airway inflammation. Clin Exp Immunol. 2019;198:390-402. doi:10.1111/cei.13362

134. Haeberlein S, Obieglo K, Ozir-Fazalalikhan A, et al. Schistosome egg antigens, including the glycoprotein IPSE/alpha-1, trigger the development of regulatory B cells. PLoS Pathog. 2017;13:e1006539. doi:10.1371/journal.ppat.1006539

135. Osbourn M, Soares DC, Vacca F, et al. HpARI protein secreted by a helminth parasite suppresses interleukin-33. Immunity. 2017;47:739-751 e735. doi:10.1016/j.immuni.2017.09.015

136. Vacca F, Chauche C, Jamwal A, et al. A helminth-derived suppressor of ST2 blocks allergic responses. Elife. 2020;9. doi:10.7554/eLife.54017

137. Li L, Shan W, Zhu H, et al. SJMHE1 peptide from Schistosoma japonicum inhibits asthma in mice by regulating Th17/Treg cell balance via miR-155. J Inflamm Res. 2021;14:5305-5318. doi:10.2147/JIR.S334636

138. Shan W, Zhang W, Xue F, et al. Schistosoma japonicum peptide SJMHE1 inhibits acute and chronic colitis induced by dextran sulfate sodium in mice. Parasit Vectors. 2021;14:455. doi:10.1186/s13071-021-04977-y

139. Bancroft AJ, Levy CW, Jowitt TA, et al. The major secreted protein of the whipworm parasite tethers to matrix and inhibits interleukin-13 function. Nat Commun. 2019;10:2344. doi:10.1038/s41467-019-09996-z

140. Wang L, Xie H, Xu L, et al. rSj16 protects against DSS-induced colitis by inhibiting the PPAR-alpha signaling pathway. Theranostics. 2017;7:3446-3460. doi:10.7150/thno.20359

141. Ebner F, Lindner K, Janek K, et al. A helminth-derived chitinase structurally similar to mammalian chitinase displays immunomodulatory properties in inflammatory lung disease. J Immunol Res. 2021;2021:6234836. doi:10.1155/2021/6234836

142. Zhu L, Liu J, Dao J, et al. Molecular characterization of S. japonicum exosome-like vesicles reveals their regulatory roles in parasite-host interactions. Sci Rep. 2016;6:25885. doi:10.1038/srep25885

143. Kuipers ME, Nolte-'t Hoen ENM, van der Ham AJ, et al. DC-SIGN mediated internalisation of glycosylated extracellular vesicles from Schistosoma mansoni increases activation of monocyte-derived dendritic cells. J Extracell Vesicles. 2020;9:1753420. doi:10.1080/ 20013078.2020.1753420

144. Buck AH, Coakley G, Simbari F, et al. Exosomes secreted by nematode parasites transfer small RNAs to mammalian cells and modulate innate immunity. Nat Commun. 2014;5:5488. doi:10.1038/ncomms6488 
145. Tanaka A, Allam V, Simpson J, et al. The parasitic 68-mer peptide FhHDM-1 inhibits mixed granulocytic inflammation and airway hyperreactivity in experimental asthma. J Allergy Clin Immunol. 2018;141:2316-2319. doi:10.1016/j.jaci.2018.01.050

146. Coronado S, Barrios L, Zakzuk J, et al. A recombinant cystatin from Ascaris lumbricoides attenuates inflammation of DSS-induced colitis. Parasite Immunol. 2017;39:e12425. doi:10.1111/pim.12425

147. Aksoy E, Zouain CS, Vanhoutte F, et al. Double-stranded RNAs from the helminth parasite Schistosoma activate TLR3 in dendritic cells. $J$ Biol Chem. 2005;280:277-283. doi:10.1074/jbc.M411223200

\section{Publish your work in this journal}

The Journal of Inflammation Research is an international, peer-reviewed open-access journal that welcomes laboratory and clinical findings on the molecular basis, cell biology and pharmacology of inflammation including original research, reviews, symposium reports, hypothesis formation and commentaries on: acute/chronic inflammation; mediators of inflammation; cellular processes; molecular mechanisms; pharmacology and novel anti-inflammatory drugs; clinical conditions involving inflammation. The manuscript management system is completely online and includes a very quick and fair peer-review system. Visit http://www.dovepress.com/testimonials.php to read real quotes from published authors.

Submit your manuscript here: https://www.dovepress.com/journal-of-inflammation-research-journal 